\title{
Dynamic vergence eye movements in strabismus and amblyopia: asymmetric vergence
}

\author{
ROBERT V. KENYON, KENNETH J. CIUFFREDA, * AND LAWRENCE STARK \\ From the University of California School of Optometry, Berkeley, \\ California 94720, USA
}

SUMMARY This report investigates line-of-sight asymmetric disparity vergence in patients having either intermittent strabismus, constant strabismus with amblyopia, or amblyopia without strabismus. We find an absence of disparity vergence in all patients with strabismus and in some with amblyopia only. Accommodative vergence and saccades place the dominant eye on the targets moving in depth. These accommodative vergence responses have normal dynamic characteristics, thus indicating a properly functioning vergence motor system. We propose there is a higher-level central defect in which incoming information of one eye is suppressed, so that the disparity vergence system is rendered inoperable.

Disparity (fusional) vergence refers to changes in the line of sight of the 2 eyes during tracking of target movement in depth. Line-of-sight asymmetric disparity vergence is a special case, considered in this paper, in which target movement occurs along the line-of-sight of one eye (the 'on-axis eye'). Thus, one might naively predict that all eye movement would be confined to the fellow 'off-axis eye'. However, this prediction is incorrect for a step change in target position. Eye movement recordings in normal persons demonstrate that vergence and saccadic movements occur in each eye. ${ }^{1-3}$ After a small vergence movement ${ }^{3}$ a saccade occurs which equally distributes the retinal disparity error about the fovea of both eyes, with continuing symmetric vergence occurring until retinal disparity is reduced, so that the central target images fall within foveal Panum's areas.

Dynamic aspects of vergence in patients with strabismus and/or amblyopia have received little attention in the past. Recently Kenyon and colleagues $^{4-7}$ investigated symmetric disparity vergence and accommodative vergence in such patients. They

\footnotetext{
*Now at State College of Optometry, State University of New York, 100 East 24th Street, New York, NY 10010, USA.

Correspondence to Dr Robert V. Kenyon, Massachusetts Institute of Technology, Building 37-215, Department of Aeronautics and Astronautics, Cambridge, MA 02139, USA.
}

found accommodative vergence to substitute for the lack of disparity vergence while tracking targets in depth. In this report we explore the generality of this substitution mechanism in the case of line-ofsight asymmetric disparity vergence and discuss qualitative and quantitative aspects of the responses in patients having either intermittent strabismus, constant strabismus with amblyopia, or amblyopia without strabismus.

\section{Materials and methods}

Binocular horizontal eye position was monitored by an infrared reflection technique. ${ }^{8}$ The recording system had an overall band width of 150 hertz $(\mathrm{Hz})$, a linear range of at least \pm 5 degrees, and a noise level of $6 \mathrm{~min}$ arc. Our recording method does not distinguish between eye rotation and eye translation. Large transitional movements could introduce artefacts in our eye movement recordings. However, Krishman and Stark ${ }^{9}$ demonstrated that eye translation for a 10-degree disparity vergence movement was negligible; all vergence movements in our patients were less than $10^{\circ}$.

Targets were placed along the line of sight of either the dominant or nondominant eye at distances of 50 and $25 \mathrm{~cm}$ from the estimated centre of rotation of the eye producing disparity of approximately $6 \cdot 8^{\circ} .4$ Targets were carefully adjusted in the horizontal and vertical planes to minimise occurrence of eye movements resulting from target misalign- 
Table 1 Clinical data of subjects

\begin{tabular}{|c|c|c|c|c|c|c|c|c|c|}
\hline Subject & Age & Prescription & $\begin{array}{l}\text { Visual } \\
\text { acuity }\end{array}$ & $\begin{array}{l}\text { Vergence } \\
\text { abnormality } \\
(p d)\end{array}$ & $\begin{array}{l}\text { Eccentric } \\
\text { fixation }(p d)\end{array}$ & $\begin{array}{l}\text { Corres- } \\
\text { pondence } \\
\text { and } \\
\text { stereoacuity* }\end{array}$ & $\begin{array}{l}\text { Previous } \\
\text { surgery } \\
\text { or } \\
\text { therapy }\end{array}$ & $\begin{array}{l}\text { Vergence } \\
40 \mathrm{~cm} \\
\text { Base in }(p d) \\
\text { Base out }(p d)\end{array}$ & $\begin{array}{l}\text { Abilities } \\
6 \mathrm{~m} \\
\text { Base in }(p d) \\
\text { Base out }(p d)\end{array}$ \\
\hline \multicolumn{7}{|c|}{ Constant strabismus amblyopia } & \multicolumn{3}{|c|}{ Break/refusion } \\
\hline 1 & 23 & $\begin{array}{l}\text { LE }+3.75=-0.50 \times 165 \\
\text { RE }+0.50\end{array}$ & $\begin{array}{l}20 / 30 \\
20 / 15\end{array}$ & 18 ET LE & 1 nasal LE & $\overline{400^{\prime \prime}}$ & $\begin{array}{l}\text { Age } 6 \\
\text { surgery }\end{array}$ & $\begin{array}{c}18 / 10 \\
6 / 2\end{array}$ & - \\
\hline 2 & 15 & $\begin{array}{ll}\text { LE } & -1 \cdot 50 \\
\text { RE } & -1 \cdot 75\end{array}$ & $\begin{array}{l}20 / 122 \\
20 / 20\end{array}$ & $\begin{array}{l}10 \text { ET LE; } \\
1 \text { HT LE }\end{array}$ & $\begin{array}{l}2 \cdot 5 \text { nasal; } \\
2 \text { superior } L E\end{array}$ & $\begin{array}{l}\text { ARC } \\
300^{\prime \prime}\end{array}$ & None & $\begin{array}{l}24 / 14 \\
24 / 15\end{array}$ & $\begin{array}{c}15 / 10 \\
6 / 3\end{array}$ \\
\hline 3 & 33 & $\begin{array}{l}\mathrm{LE}+0.75=-0.50 \times 40 \\
\mathrm{RE}+0.25=-0.50 \times 180\end{array}$ & $\begin{array}{l}20 / 630 \\
20 / 10\end{array}$ & $\begin{array}{l}\text { 5-6 ET LE; } \\
2 \text { HT LE }\end{array}$ & $\begin{array}{l}2 \cdot 5-3 \cdot 5 \text { nasal; } \\
3-4 \text { superior LE }\end{array}$ & $\overline{-}$ & $\begin{array}{l}\text { Age } 8 \\
\text { surgery }\end{array}$ & - & - \\
\hline \multicolumn{10}{|c|}{ Amblyopia without strabismus } \\
\hline 4 & 24 & $\begin{array}{l}\text { LE }-0.75=-2.00 \times 90 \\
\text { RE pl }=-0.50 \times 19\end{array}$ & $\begin{array}{l}20 / 38 \\
20 / 20\end{array}$ & None & $\begin{array}{l}2 \text { nasal; } 2 \\
\text { inferior } L E\end{array}$ & $\begin{array}{l}\text { NRC } \\
100^{\prime \prime}\end{array}$ & None & $\begin{array}{l}24 / 16 \\
14 / 10\end{array}$ & $\begin{array}{c}36 / 26 \\
4 / 2\end{array}$ \\
\hline 5 & 22 & $\begin{array}{l}\text { LE }-7.75=-3.00 \times 180 \\
\text { RE }-4.00=-0.75 \times 135\end{array}$ & $\begin{array}{l}20 / 400 \\
20 / 15\end{array}$ & None & - & - & None & - & - \\
\hline \multicolumn{10}{|c|}{ Intermittent strabismus } \\
\hline 6 & 13 & $\begin{array}{l}\text { LE + } 0.75 \\
\text { RE + 0.50 }\end{array}$ & $\begin{array}{l}20 / 20 \\
20 / 20\end{array}$ & $\begin{array}{l}20 \text { ET RE; } \\
6 \text { HT RE }\end{array}$ & Jerk nyst. & $\begin{array}{l}\text { UHARC }+ \\
-\end{array}$ & $\begin{array}{l}\text { Age } 2 \\
\text { surgery }\end{array}$ & - & - \\
\hline 7 & 31 & $\begin{array}{l}\text { LE }-5.00 \\
\text { RE }-4.50=-0.75 \times 20\end{array}$ & $\begin{array}{l}20 / 20 \\
20 / 20\end{array}$ & $15 \times \mathrm{XT}$ LE & $\begin{array}{l}\text { Central, steady } \\
\text { LE, RE }\end{array}$ & $\begin{array}{l}\text { ARC } \\
40^{\prime \prime}\end{array}$ & $\begin{array}{l}\text { Age } 16 \\
\text { surgery }\end{array}$ & $\begin{array}{l}\text { 40/doubled } \\
24 / \text { doubled }\end{array}$ & $\begin{array}{r}\text { 40/doubled } \\
\text { 8/doubled }\end{array}$ \\
\hline \multicolumn{10}{|c|}{ Control subjects } \\
\hline 8 & 29 & $\begin{array}{l}\text { LE plano } \\
\text { RE plano }\end{array}$ & $\begin{array}{l}20 / 20 \\
20 / 20\end{array}$ & None & None & $\begin{array}{l}\text { NRC } \\
40^{\prime \prime}\end{array}$ & None & - & - \\
\hline 9 & 23 & $\begin{array}{l}\mathrm{LE}+8.0=0.25 \times 175 \\
\mathrm{RE}+8.0\end{array}$ & $\begin{array}{l}20 / 20 \\
20 / 20\end{array}$ & None & None & $\begin{array}{l}\text { NRC } \\
40^{\prime \prime}\end{array}$ & None & - & - \\
\hline
\end{tabular}

At least as indicated. pd = Prism dioptre. +Unharmonious ARC.

ment. Targets, consisting of small lucite plates with crosses etched on the front surfaces, subtended angles of 1.5 and $3.0^{\circ}$ for the far and near distances respectively. A miniature bulb was installed at the base of each lucite plate to illuminate the target, $0.5 \log \mathrm{ft}$-lamb, which proved to be highly visible and provided a good accommodation stimulus to the patients in the darkened (low photopic) test room. (SI conversion: candela $/ \mathrm{m}^{2}=$ foot-lambert $\times$ 3.426.)

The stimulus was presented as follows. Targets were alternately illuminated in a pseudorandom sequence by the experimenter. Patients and control subjects were instructed to keep the illuminated target clear at all times (and single if diplopia was appreciated). This procedure was performed during either binocular viewing or monocular viewing with the 'on-axis eye'.

Seven patients having either intermittent strabismus, constant strabismus with amblyopia, or amblyopia without strabismus participated in the study. They were recruited from the clinics at the School of Optometry. All had a thorough vision examination and were free of ocular or neurological disease. Patients' ages ranged from 13 to 33 years, with a mean age of 23 years. Two adult control subjects were also tested. See Table 1 for pertinent clinical findings of each patient and control subject.

\section{Results}

ASYMMETRIC VERGENCE: DOMINANT EYE

Normal binocular eye movement responses to asymmetric stimuli consisted of approximately equal vergences in each eye and a binocular saccade as demonstrated by our control subject's response (Fig. 1a). The binocular convergence movement, $300 \mathrm{~ms}$ after the target change, is combined with a rightward saccade $120 \mathrm{~ms}$ later to place each fovea on the target; the saccade distributes the retinal disparity error symmetrically about the foveas of the 2 eyes. For normal subjects the relative vergence amplitude (ratio of smaller to larger vergence amplitude between the 2 eyes) ranged from $60 \%$ to $100 \%$. Moreover, relative saccadic amplitude (ratio of smaller to larger saccade amplitude between the 2 eyes) during vergence ranged as expected from $20 \%$ to $100 \%{ }^{4-71011}$ Responses for our control subjects showed both normal variation of relative vergence amplitudes and unequal saccadic amplitudes during vergence.

In contrast, patients with strabismus showed a 

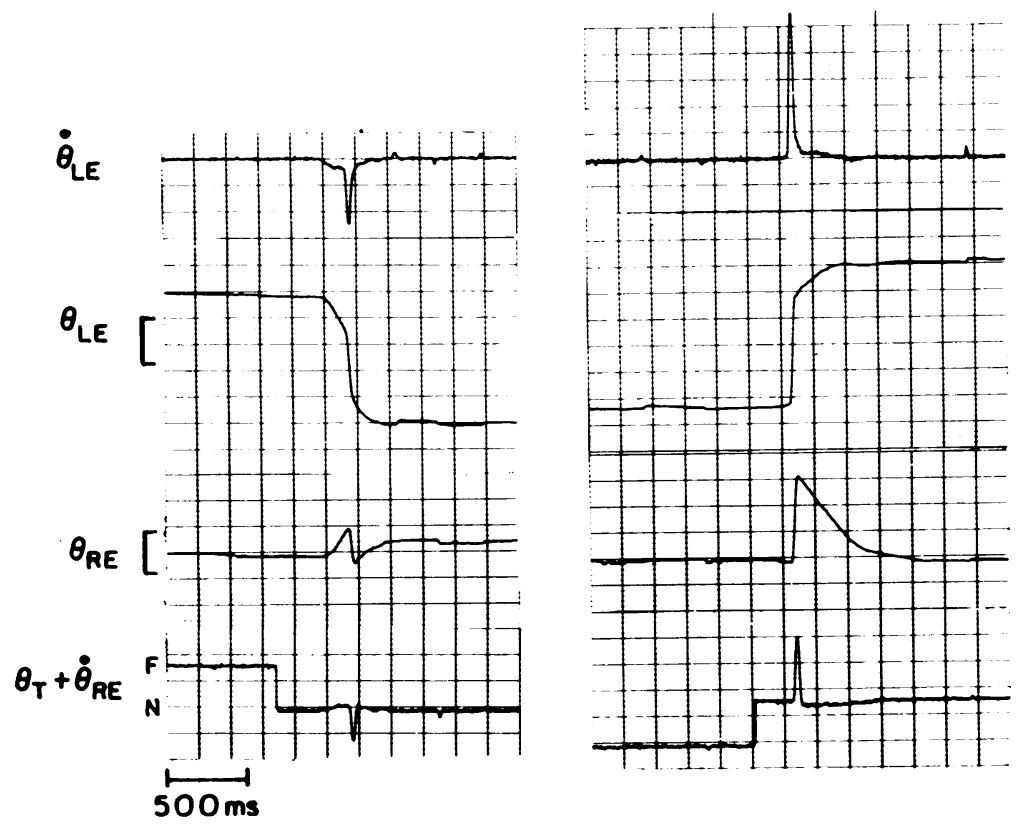

Fig. 1 Asymmetric vergence response under binocular viewing conditions with targets aligned along the dominant eye. Symbols and conventions: $\theta_{l e}$ and $\theta_{\text {re }}$ are left and right eye positions, $\dot{\theta}_{l e}$ and $\dot{\theta}_{\text {re }}$ are left and right eye velocity, $\theta_{t}=$ target position, $\theta_{t}+\dot{\theta}_{r e}=$ linear summation of $\theta_{t}$ and $\dot{\theta}_{\text {re }}$ in one trace: $F=$ far target, $N=$ near target, calibration bars represent 2 degrees. Deflections up are left.

(a) Control subject 9. Normal response to asymmetric vergence stimuli evident, showing large saccade and vergence to place fovea of each eye on target. Left response is convergence and right response is divergence.

Fig. 1 (b) Patient 7. Left intermittent strabismus (exotropia). Normal acuity (20/20) each eye. Response shows lack of equal vergence amplitudes in each eye. Small corrective saccades are the same magnitude as the vergence in the dominant eye. characteristic of accommodation rather than asymmetric vergence responses.

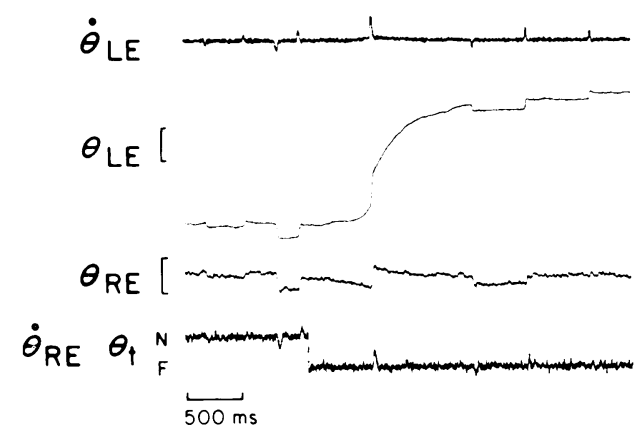

completely different response under the same asymmetric stimulus conditions. Eye movement responses in a patient with intermittent strabismus, for example (Fig. 1b), consisted of markedly unequal vergence amplitudes in each eye; relative vergence amplitude equalled $20 \%$, with the smaller movement occurring in the 'on-axis' eye. Further, the saccade no longer distributed retinal disparity symmetrically about the foveas. Instead, the saccades corrected only position errors induced by small vergence movements in the dominant eye. Patients with constant strabismus and amblyopia showed similar responses (Fig. 1c); neither group's responses were dependent upon angle of strabismus or depth of amblyopia.

Unlike patients with strabismus, not all patients having only amblyopia exhibited an absence of disparity vergence. Of 2 amblyopes studied, one showed an intermittent normal vergence, and the other consistently showed a lack of disparity vergence. Fig. 1d shows the response of an amblyopia patient (20/40) who intermittently made normal asymmetric vergence $(15 \%$ of the time), mostly to convergence stimuli $(70 \%$ of the time). Normal asymmetric vergence characteristics are evident: approximately equal vergence movements in each eye and a binocular saccade. The divergence, however, shows highly unequal vergence in each eye, with relative vergence amplitude equalling $15 \%$. This abnormal divergence response is similar to those found in our patients with strabismus. Our second amblyope, patient $5(20 / 400)$, showed 
Fig. 1 (c) Patient 1. Constani strabismus (esotropia) with amblyopia (20/30) in left eye. Note inequality of vergence amplitudes during both convergence and divergence responses. Small saccades correct position errors due to vergence in dominant eye.
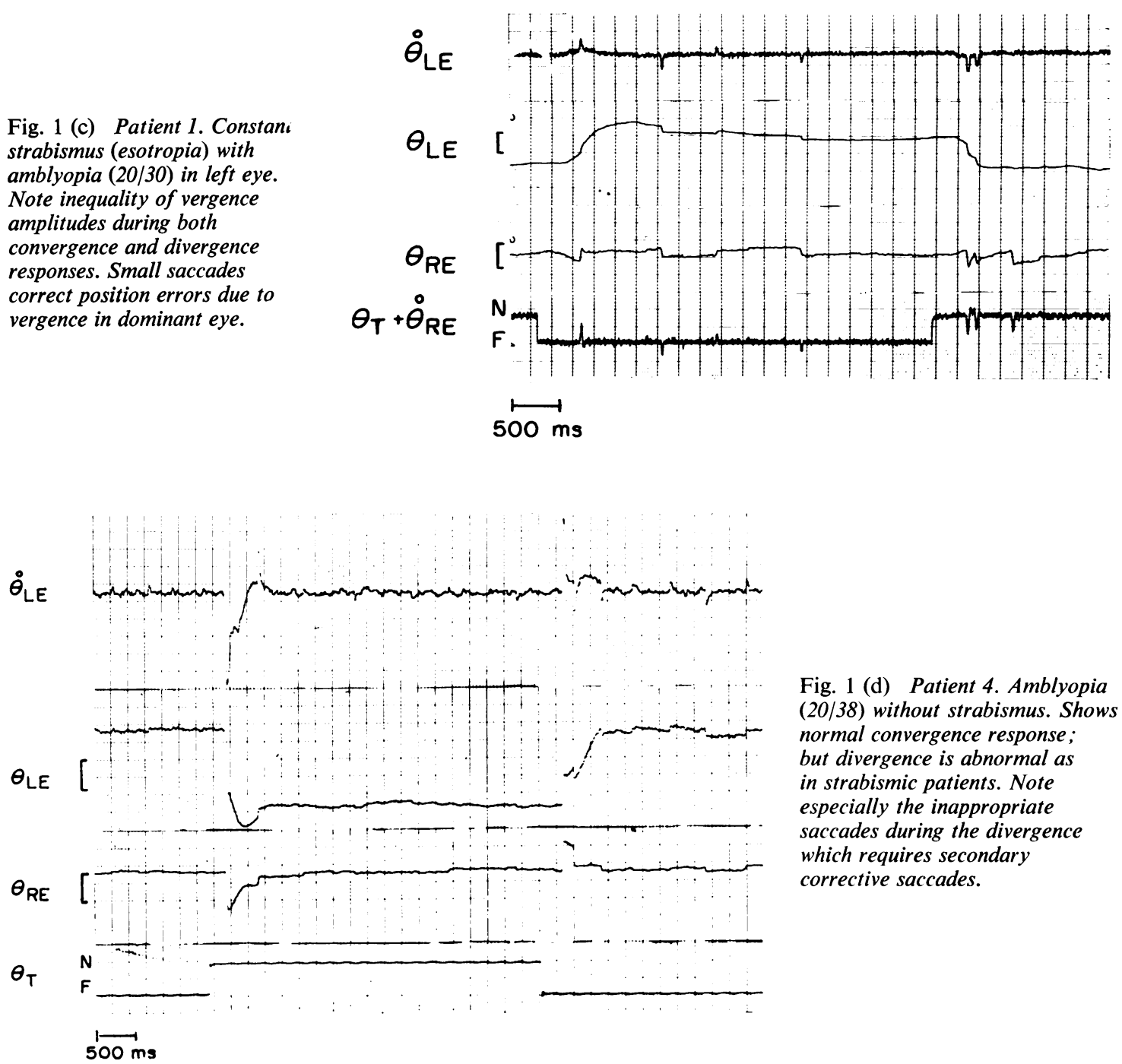

abnormal asymmetric vergence movements, similar to our strabismic patient, at all times.

\section{ACCOMMODATIVE VERGENCE:}

DOMINANT EYE

Müller ${ }^{12}$ first described the classic accommodative vergence stimulus paradigm: targets aligned along the line-of-sight of the dominant eye with the 'offaxis' eye occluded. Under these conditions normal subjects respond with unequal vergence amplitudes in each eye. ${ }^{10}$ Specifically, vergence amplitudes in the viewing eye equal a small percentage $(12 \%)$ of the vergence in the covered eye, with corrective movements keeping the target within the fovea of the viewing eye. Our control subject's responses (Fig. 2a) provide a good example of normal accommodative vergence movements.

Interestingly, these characteristics also describe our patients' responses to targets along the line-ofsight of the dominant eye under binocular viewing conditions (Figs. 1b-d). In fact comparisons between control subjects' accommodative vergence responses and these patients' asymmetric vergence responses showed both a qualitative and quantitative similarity to exist. For example, our strabismus patient's relative vergence amplitude did not exceed $25 \%$, and small corrective movements kept the target on the dominant eye's fovea. 

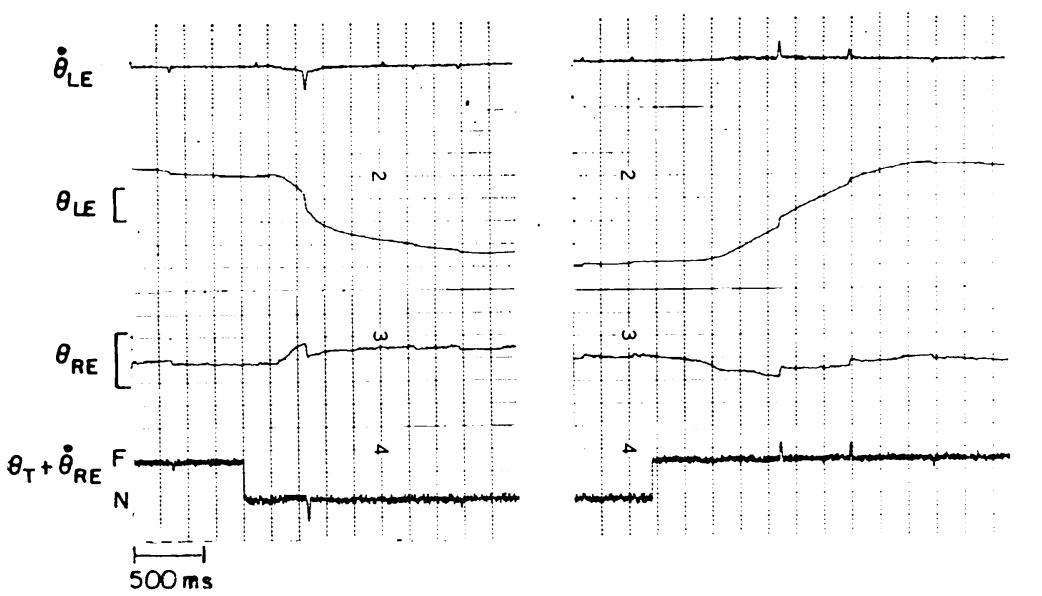

(a) Control subject exhibits normal accommodative vergence movements (explained in text).

Fig. 2 Responses to line-ofsight accommodative vergence along dominant eye.
Fig. 2 (b) Patient 7. Left intermittent strabismus (exotropia). Normal visual acuity (20/20) each eye. Shows normal accommodative vergence movements. Note similarity to patient's asymmetric vergence in Fig. $1 b$.

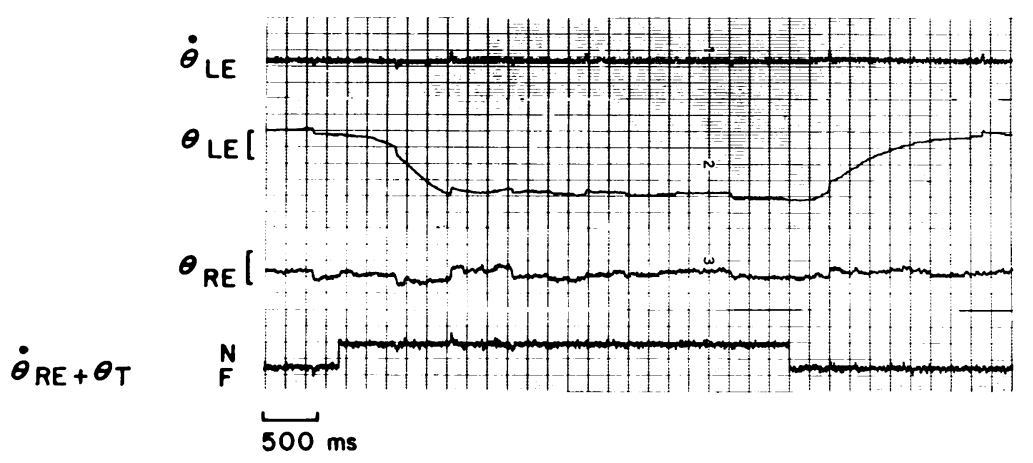

When the patients' nondominant eye was covered and the targets were still along the dominant eye, the resultant accommodative vergence responses (Fig. 2b) were similar to the accommodative vergence of our control subject (Fig. 2a) and showed little change from these patients' own responses under binocular viewing conditions. Comparison of accommodative vergence responses from patient 7 (Fig. 2b) with its own asymmetric vergence responses (Fig. 1b) and with normal subjects' accommodative vergence responses (Fig. 2a) shows the equivalence of all 3 responses.

\section{ASYMMETRIC VERGENCE:}

NONDOMINANT EYE

To ensure that the asymmetric vergence responses of the patients were not due to dominant eye stimulation, targets were aligned along the nondominant eye and the experiment repeated. Fig. 3a shows that the characteristic smaller vergence in the dominant eye continues to occur even with the targets along the nondominant eye for this inter- mittent strabismic patient. In addition to the unequal vergence a saccade places the dominant eye near the target; the saccade and the vergence combine to fixate the dominant eye on the target. At first glance these response looked qualitatively similar to normal asymmetric vergence, but when the vergence amplitudes were analysed the abnormal unequal asymmetric vergence was evident; vergence in the dominant eye equalled $10 \%$ of that in the nondominant eye in this condition. Similar responses were recorded in patients having constant strabismus with amblyopia and amblyopia only.

\section{ACCOMMODATIVE VERGENCE:}

NONDOMINANT EYE

When targets were aligned along the nondominant eye and the dominant 'off-axis' eye was covered, the accommodative vergence response appeared to be absent or grossly abnormal in deep amblyopia and to be unrelated to the presence of strabismus. Fig. 4a shows accommodative vergence responses in patient 7 (intermittent strabismus). These responses com- 
Fig. 3 Asymmetric vergence responses in 3 patients representing each diagnostic group. Targets aligned along line of sight of nondominant eye.

(a) Patient 7. Left intermittent strabismus (exotropia); normal visual acuity (20/20) each eye. Shows large saccades in each eye; vergence amplitudes remain unequal with smaller amplitude in dominant eye. Saccade and vergence serves to place dominant eye on target. Characteristic unequal vergence in dominant eye asymmetric vergence responses are shown in these records.
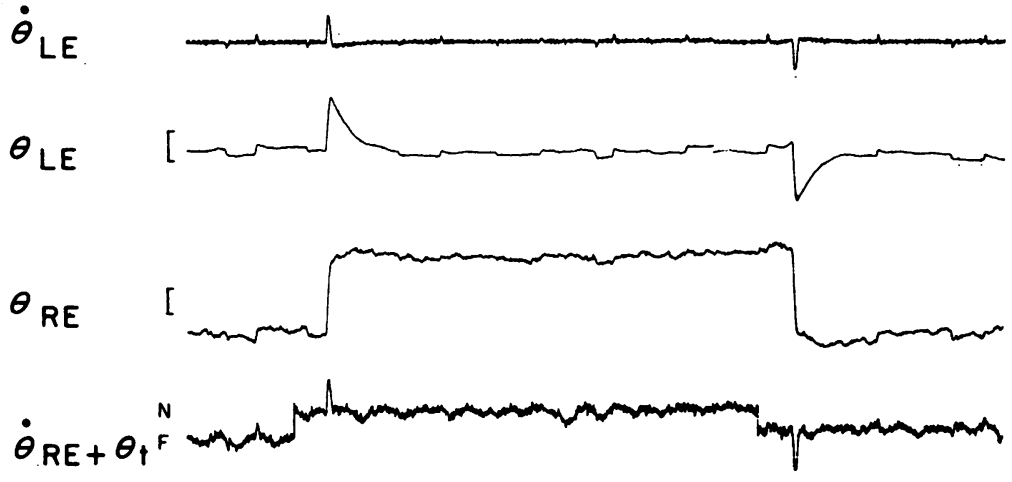

$500 \mathrm{~ms}$ pared with those along the dominant eye (Fig. 2a) showed no differences in response amplitude or dynamics. With a small amount of amblyopia as in patient $4(20 / 40)$ (Fig. 4b) no effect is evident on the accommodative vergence response. Patient 2 with constant strabismus and moderate amblyopia (20/122) also showed normal accommodative vergence when the nondominant eye alone received the stimuli. However, patient 5 with amblyopia only (20/400) (Fig. 4c) showed markedly reduced accommodative vergence responses in the covered eye.
Another patient (3) with constant strabismus and deep amblyopia (20/630) also lacked evidence of normal accommodative vergence amplitude in the covered eye. These findings showed the pronounced effect deep amblyopia had on the accommodative vergence system. However, a portion of this reduction in amplitude of accommodative vergence can be attributed to eccentric fixation and/or increased drift amplitude in the amblyopic eye. ${ }^{13}$

To summarise, all patients with strabismus and some with amblyopia only showed accommodative 


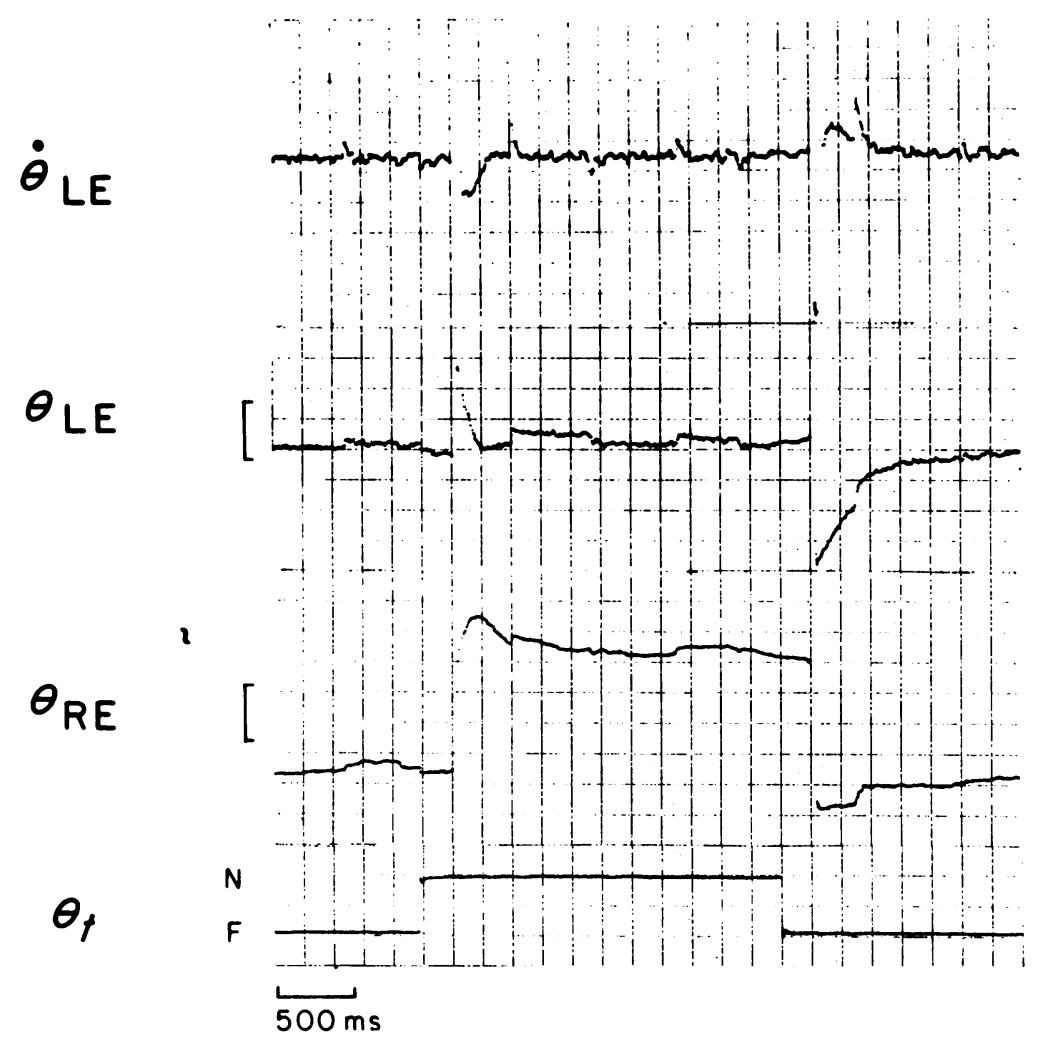

Fig. 3 (c) Patient 4 (amblyopia without strabismus) shows responses similar to patients in other two diagnostic groups (Fig. $3 a, b)$. However, note normal asymmetric vergence for convergence but not divergence.

vergence rather than asymmetric disparity vergence when attempting to track accurately real targets moving in depth with both eyes open. With the stimulus along the line-of-sight of the dominant eye, under either monocular or binocular viewing conditions, most patients' responses consisted of accommodative vergence (and a saccade). Similar responses were obtained for nondominant eye target alignment, except for patients with deep amblyopia. For these patients little or no vergence was evident in the covered eye during accommodative vergence testing.

\section{Discussion}

Our conclusion that patients with strabismus and amblyopia use accommodative vergence rather than disparity vergence to track asymmetric vergence stimuli was derived mainly from qualitative and quantitative comparisons between patients' eye movements under binocular conditions and control subject's responses under binocular and monocular viewing conditions. Patients' responses to binocular stimuli were very different from control subject's responses to such stimuli, yet these same patient responses agreed very closely with control subject responses to monocular stimuli. These monocular conditions lacked any disparity vergence stimulus, and yield only an accommodative vergence response. Thus, we reasoned that these similarities indicate an inability on the part of our patients to process disparity information present under binocular conditions, leaving target blur to drive vergence through its synkinetic link with accommodation. Further support for this hypothesis was evidenced by the similarities between patient responses to monocular and binocular stimuli. Preventing the introduction of disparity stimuli by covering the nondominant eye had no effect on the patients' responses. Furthermore, both monocular and binocular stimuli elicited responses with normal accommodative vergence characteristics. Overall, these results on asymmetric vergence showing an absence of disparity vergence complement and generalise our recent finding of a loss of disparity vergence under symmetric conditions.

Identifying the deficiencies that account for this absence of disparity vergence is a difficult task. Nevertheless, some conclusions are possible from the data presented here. A purely motor dysfunction located in the extraocular muscles, oculomotor neurons, or brainstem areas is unlikely, since the 
Fig. 4 Accommodative vergence responses in 3 patients representing each diagnostic group. Targets aligned along line of sight of nondominant eye, with fellow eye covered. Shows effect of deep amblyopia on accommodative vergence.

(a) Patient 7. Left intermittent strabismus (exotropia); normal visual acuity (20/20) each eye. Normal accommodative vergence amplitudes and dynamics in the nondominant eye shown here, similar to that found in the dominant eye (Fig. 2b).

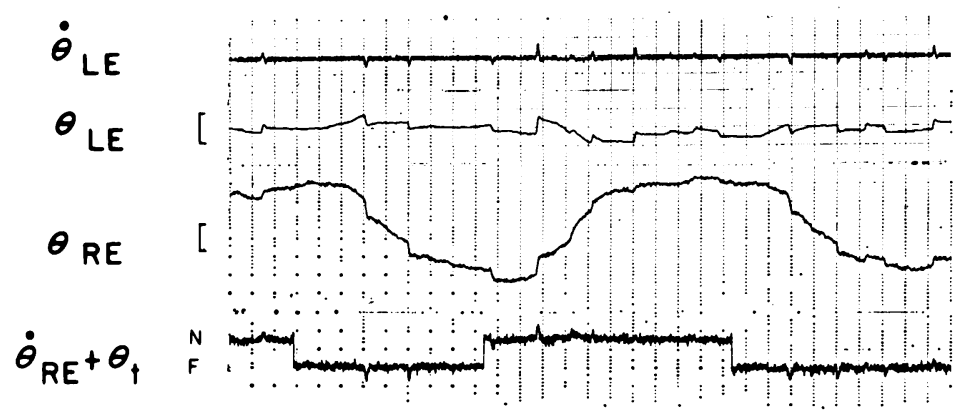

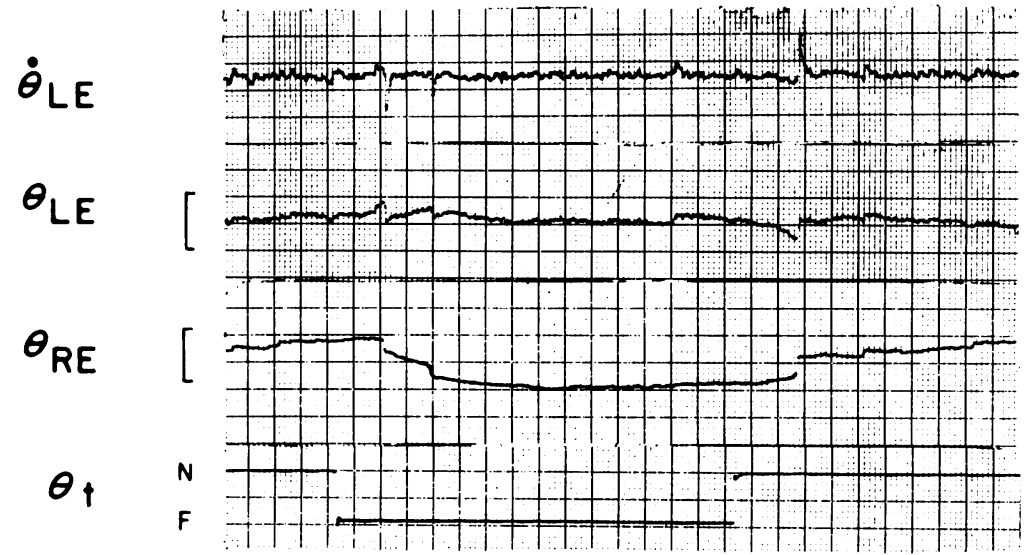

Fig. 4 (b) Patient 4. Amblyopia (20/38) without strabismus.

Normal accommodative vergence amplitude and dynamics; similar to dominant eye responses

(Fig. 2d).

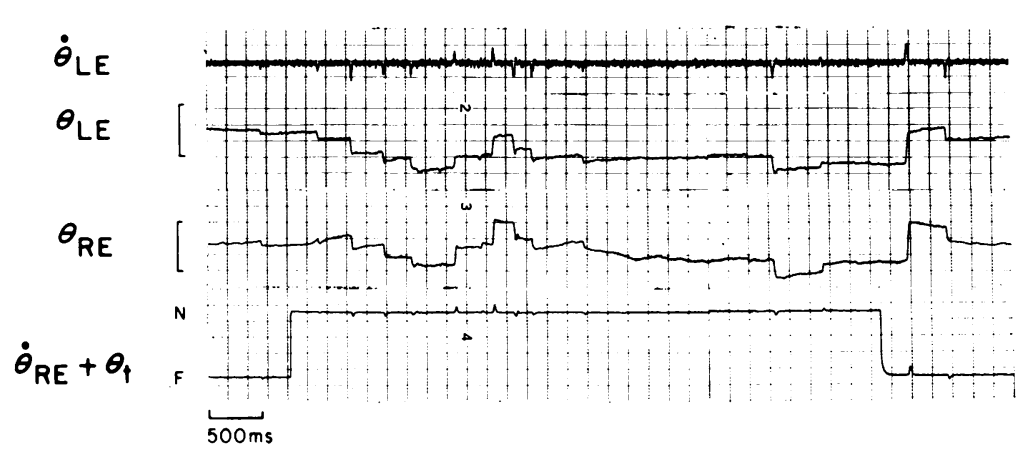

Fig. 4 (c) Patient 5. Amblyopia (20/400) without strabismus. No discernible normal accommodative vergence response evident.

accommodative vergence responses that were recorded under binocular and monocular conditions had normal dynamics and latencies. Moreover, some patients showed both presence and absence of disparity vergence responses under binocular conditions. Sensory dysfunction located in the retina, lateral geniculate nucleus, or in area 17 of the primary visual cortex appears not to be the site of deficiency either, since patient 7 with intermittent strabismus without amblyopia had intermittently functioning stereopsis and sensory fusion, but with complete absence of disparity vergence (Fig. 1b). Further, after orthoptic therapy for deep amblyopia (attributed to anisometropia and not strabismus) 
visual acuity can be $20 / 20$ with nearly normal stereopsis but with absence of disparity vergence. Yet some amblyopes with 20/40 visual acuity had normal disparity vergence (Fig. 2b). Central (higher sensorimotor processing) deficiency perhaps in areas 18 and 19 of the visual cortex, area 22 of parietal cortex, and higher supernuclear centres such as the superior colliculus ${ }^{14}$ and pulvinar, is much more difficult to approach either clinically or experimentally in lower animals and man. Interestingly, Blake and Lehmkuhle ${ }^{15}$ have shown psychophysically in humans normal grating after-effects, in spite of the presence of suppression associated with strabismus, ${ }^{16}{ }^{17}$ suggesting the site of suppression is beyond the site (probably area 17 of the visual cortex) of the grating after-effect. We believe that a similar higher level central site is responsible for suppression of disparity information used in control of vergence movements.

Neurophysiological and anatomical studies in animals have also added to our knowledge of pathophysiological effects of strabismus and amblyopia. Lund et al. ${ }^{18}$ found anatomical changes in spatial distribution of callosal terminals from contralateral cortex in strabismic animals; terminations of these fibres were displaced from their normal location along the 17-18 border. Others, ${ }^{19} 20$ who have produced strabismus and amblyopia in animals by depriving them of normal visual experience during critical development periods, have found physiological changes in the cortex, most notable is reduction in number of cells responding to binocular stimuli.

Lastly, our findings have at least 2 direct clinical applications: (1) the 4-prism dioptre base-out test and (2) fusion training. To review briefly: (1) The 4-prism dioptre base-out test is used to detect the presence of small central binocular suppression scotomas in small-angle esotropes ${ }^{21}$ by placing a 4-dioptre prism base-out before one eye during binocular viewing and thus optically producing an asymmetric disparity ('fusional') vergence condition. If the prism is placed over either eye of an individual with normal binocular vision, an asymmetric disparity vergence response consisting of a binocular saccade and vergence results. If the prism is placed over the dominant eye of an esotrope, however, only the saccade should occur to correct the position error in that eye due to prism image displacement. If the prism is now placed before the nondominant eye of an esotrope, no eye movements occur if the target image is displaced within the region of the suppression scotoma. If the clinical test produced both disparity and blur (and not disparity alone), as was true for our test conditions as well as occurs in real-life conditions, the anticipated response in the esotrope would be a saccade plus accommodative vergence (both driven by the dominant eye) as was found in our experiments. (2) Fusion training in instrument and free-space ${ }^{22}$ is commonly used in strabismics, once visual acuity is improved and suppression is minimised. In the amblyoscope second and third degree fusion targets may be used with the carriage arms at a variety of positions, thus producing symmetric as well as asymmetric disparity vergence conditions, of which both static (which is measured clinically) and dynamic (which we present here) responses should be thoroughly understood by the clinician. Similarly, in free space, prisms of various magnitudes are placed before either or both eyes creating symmetric and asymmetric vergence conditions. Comparison of responses in the "reduced environment' of the amblyoscope, in which targets presented to the nondominant eye can be flashed or luminance increased in order to overcome ('break') suppression and thus potentially allow for a fusion response, can be compared to responses obtained under 'real life' symmetric and asymmetric vergence conditions produced by prisms or real target movement, similar to the manner of testing used by us in our patients. Thus a goal of treatment in strabismics and amblyopes would be normal static and dynamic fusional responses in both instrument and free space for both symmetric and asymmetric disparity vergence stimulus conditions.

The authors are grateful to Dr Kenneth Polse, clinic director, and Dr J. David Grisham for their assistance in obtaining patients for this study. This research was supported by NIH grant EY00076 (K.J.C. and R.U.K.) and the Auxiliary to the American Optometric Association (K.J.C.).

\section{References}

1 Westheimer G, Mitchell AM. Eye movement responses to convergent stimuli. Arch Ophthalmol 1956; 55: 848-56.

2 Riggs LA, Niehl EW. Eye movements recorded during convergence and divergence. J Opt Soc Am 1960; 50: 913-20.

3 Yarbus AL. Eye Movements and Vision. New York: Plenum Press, 1967.

4 Kenyon RV. Vergence eye movements in strabismus and amblyopia. Ph.D. dissertation. Berkeley: University of California, 1978.

5 Kenyon RV, Ciuffreda KJ, Stark L. Dynamic vergence eye movements in strabismus and amblyopia: symmetric vergence. Invest Ophthalmol Visual Sci 1980; 19: 60-74.

6 Kenyon RV, Ciuffreda KJ, Stark L. Unequal saccades during vergence. Am J Optom Physiol Opt 1980; 57: 20-37.

7 Kenyon RV, Ciuffreda KJ, Stark L. The unexpected role for normal accommodative vergence in strabismus and amblyopia. Am J Optom Physiol Opt 1980; 57: 10-20.

8 Stark L, Vossius G, Young LR. Predictive control of eye tracking movements. Inst Res Electron Trans Human Factor Electron 1962; HFE-3: 52-57.

9 Krishnan VV, Stark L. A heuristic model of the vergence eye movement system. Inst Electrical Electron Engr 
Trans Biomed Engineering 1977; BME-24: 4449

10 Kenyon RV, Ciuffreda KJ, Stark L. Binocular eye movements during accommodative vergence. Vision Res 1978; 18: 545-65.

11 Ono H, Nakamizo S, Steinbach M. Nonadditivity of vergence and saccadic eye movements. Vision Res 1978; 18: 735-9.

12 Müller J. Elements of Physiology. Trans W. Baly. London: Taylor and Walton, 1843: 2: 1147-8.

13 Ciuffreda KJ, Kenyon RV, Stark L. Increased drift in amblyopic eyes. Br J Ophthalmol 1980; 64: 7-14.

14 Ciuffreda KJ, Kenyon RV, Stark L. Increased saccadic latencies in amblyopic eyes. Invest Ophthalmol Visual Sci 1978; 17: 697-702.

15 Blake R, Lehmkuhle SW. On the site of strabismic suppression. Invest Ophthalmol Visual Sci 1976; 15: 660-3.

16 Travers T. Suppression of vision in squint and its asso- ciation with retinal correspondence and amblyopia. Br J Ophthalmol 1938; 22: 577-609.

17 Jampolsky A. Characteristics of suppression in strabismus. Arch Ophthalmol 1955; 54: 683-96.

18 Lund RD, Mitchell DE, Henry GH. Squint-induced modification of callosal connections in cat. Brain Res 1978 ; 144: 169-72.

19 Hubel D, Wiesel T. Binocular interactions in striate cortex of kittens reared with artificial squint. $J$ Neurophysiol 1965; 28: 1041-59.

20 von Noorden GK, Dowling JE, Furgesion DC. Experimental amblyopia in monkeys. II. Behavioral studies in strabismus and amblyopia. Arch Ophthalmol 1970; 84: 215-20.

21 von Noorden GK, Maumenee AE. Atlas of Strabismus. St Louis: Mosby, 1967: 60-1.

22 Griffin JR. Binocular anomalies: Procedures for Vision Therapy. Chicago: Professional Press, 1976: 241-9. 